\title{
A LUTA DOS MOVIMENTOS SOCIOTERRITORIAIS CAMPONESES PELO DIREITO À EDUCAÇÃO DO CAMPO
}

\section{LA LUCHA DE LOS MOVIMIENTOS SOCIO-TERRITORIALES CAMPESINOS POR EL DERECHO A LA EDUCACIÓN DEL CAMPO}

\begin{abstract}
Rodrigo Simão Camacho
Universidade Federal da Grande Dourados, Faculdade Intercultural Indígena, Licenciatura em Educação do Campo, Programa de Pós-graduação em Educação e Territorialidade, Dourados, MS, Brasil. rogeo@ymail.com
\end{abstract}

\section{Resumo}

O objetivo do artigo é discutir as conquistas da Educação do Campo, enquanto política pública, tendo como protagonistas os movimentos socioterritoriais camponeses. Toda a legislação que foi sancionada a respeito da Educação do Campo é conquista de todo o Movimento da Educação do Campo, que envolve, além dos movimentos socioterritoriais camponeses, várias organizações sociais, universidades e educadores do campo (formais e não formais), representados, sobretudo, primeiramente, pela Articulação Nacional Por uma Educação do Campo e, atualmente, o Fórum Nacional da Educação do Campo (FONEC). A primeira conquista da Educação do Campo, enquanto política pública, foi o Programa Nacional de Educação na Reforma Agrária (PRONERA), que é uma política pública de Educação do Campo desenvolvida nas áreas de Reforma Agrária. A metodologia do artigo está dividida em duas partes principais. A primeira é a análise da legislação e de documentos oficiais relativos à Educação do Campo. A segunda está relacionada com a entrevista de camponeses-assentados-educandos do Curso Especial de Geografia do Pronera (CEGeo).

Palavras-chave: Legislação. Direito à Educação. Políticas Públicas. Movimentos Socioterritoriais.

\section{Resumen}

El objetivo del artículo es discutir los logros de la Educación del Campo, como política pública, con los movimientos socio-territoriales campesinos como protagonistas. Toda la legislación que se ha sancionado con respecto a la Educación del Campo es la conquista de todo el Movimiento de Educación del Campo, que involucra, además de los movimientos campesinos varias organizaciones sociales (como UNICEF), universidades y educadores rurales (formales y no formales), representados, principalmente, por la Articulación Nacional para la Educación Rural y el Foro Nacional de Educación del Campo (FONEC). El primer logro de la Educación en el campo, como política pública, fue el Programa Nacional de Educación en Reforma Agraria (PRONERA), que es una política pública de Educación en el Campo desarrollada en las áreas de la Reforma 
Agraria. La metodología del artículo se divide en dos partes principales. El primero es el análisis de la legislación y los documentos oficiales relacionados con la educación del campo. El segundo está relacionado con la entrevista a campesinos da reforma agraria que son estudiantes del Curso Especial de Geografía de Pronera (CEGeo).

Palabras clave: Legislación. Derecho a la Educación. Políticas Públicas. Movimientos Socio-Territoriales.

\section{Introdução}

Estamos vivendo nas últimas décadas um período histórico onde alternaram-se momentos de avanços e retrocessos para as classes subalternas. Marcado por ações, em que as populações do campo que lutam para conquistar e/ou resistir em seus territórios, também lutam pela garantia de direitos a uma educação de qualidade, que respeite suas identidades territoriais e de classe, seu modo de vida, que seja crítica-emancipatória e contra-hegemônica.

As ações das populações do campo são coletivas e estão organizadas em movimentos sociais que constroem/reconstroem territórios, por isso, são denominados de "movimentos socioterritoriais" (FERNANDES, 2005). Os movimentos socioterritoriais são formados a partir de ações sociopolíticas construídas por sujeitos sociais coletivos que objetivam a luta social para a conquista ou resistência territorial.

O objetivo do artigo é discutir as conquistas da Educação do Campo, enquanto política pública, tendo como protagonistas os movimentos socioterritoriais camponeses. Toda a legislação que foi sancionada a respeito da Educação do Campo é conquista de todo o Movimento da Educação do Campo, que envolve, primordialmente, os movimentos socioterritoriais camponeses - Via Campesina, Movimento dos Trabalhadores Rurais Sem Terra (MST), Movimento dos Pequenos Agricultores (MPA), Movimento dos Atingidos por Barragens (MAB), Movimento de Mulheres Camponesas (MMC), Pastoral da Juventude Rural (PJR), a Confederação Nacional dos Trabalhadores na Agricultura (Contag) -, mas também, algumas organizações sociais e/ou instituições, como o Fundo das Nações Unidas para a Infância (UNICEF) e a Conferência Nacional dos Bispos do Brasil (CNBB), docentes, discentes e pesquisadores de várias universidades públicas e educadores do campo (formais e não formais), representados, sobretudo, primeiramente, pela Articulação Nacional Por uma Educação do Campo e, atualmente, pelo Fórum Nacional da Educação do Campo (FONEC). 
Se a história do campo brasileiro é a história da luta contra o cativeiro e contra o latifúndio (FERNANDES, 2004), a Educação do Campo também é uma conquista da luta dos movimentos camponeses. A conquista da Educação do Campo perpassa a elaboração de leis que contemplem a proposta de Educação do Campo engendrada pelos movimentos socioterritoriais do campo. Neste sentido,

No que diz respeito à legislação, o movimento da Educação do Campo acumulou, a partir de suas diversas lutas (nacionais, estaduais e municipais), um conjunto importante de instrumentos legais que reconhecem e legitimam as lutas dos trabalhadores do campo, uma condição necessária para que a universalidade do direito à educação se exerça, respeitando as especificidades dos sujeitos do campo. (FONEC, 2011, p. 14).

O marco inicial na história da Educação do Campo é quando, em 1997, o Movimento dos Trabalhadores Rurais Sem Terra (MST) realizou, em conjunto com a Universidade de Brasília (UNB) e a Unicef (Fundo das Nações Unidas para a Infância), o I ENERA (I Encontro Nacional de Educadores de Reforma Agrária). O segundo marco histórico da Educação do Campo foi a I Conferência Nacional Por uma Educação Básica do Campo. Foram mil participantes reunidos em Luziânia-GO, de 27 a 31 de julho de 1998, que formaram a Articulação Nacional Por Uma Educação Básica do Campo.

A primeira conquista da Educação do Campo, enquanto política pública, foi o Programa Nacional de Educação na Reforma Agrária (PRONERA). Nasceu em 1998 da luta dos movimentos sociais e sindicais camponeses. Foi desenvolvida nas áreas de Reforma Agrária. Apesar de ter sido criado durante o mandato de Fernando Henrique Cardoso (FHC), foi durante o período do mandato de Luiz Inácio Lula da Silva (Lula) como presidente que se deu o maior número de cursos. Seu objetivo foi fortalecer os territórios camponeses em todas as suas dimensões: ambientais, econômicas, sociais, políticas, culturais e étnicas (CAMACHO, 2018).

As experiências de Educação do Campo que estão sendo desenvolvidas no Brasil, permitem que visualizemos duas características principais: a primeira é o protagonismo dos movimentos socioterritoriais na elaboração e execução, por meio da conquista de políticas públicas, e a segunda é a produção de conhecimentos educativos pelos próprios movimentos camponeses (MOLINA, 2004; CAMACHO, 2017, 2018).

Neste contexto, defendemos que a Educação do Campo é uma práxis pedagógica resultante da luta camponesa, mas também, é um instrumento da luta contra a terrritorialização do agronegócio no campo (resistência territorial), a favor da 
reterritorialização/recamponização (conquista territorial), da reprodução política, econômica, social e cultural camponesa e da sustentabilidade ambiental (CAMACHO, 2017, 2018).

Quando os movimentos socioterritoriais são protagonistas no processo de conquista e construção da Educação do Campo, pode-se estabelecer o diálogo dos saberes adquiridos na luta social, no decorrer dos processos de espacialização e territorialização do Movimento, com os conhecimentos técnicos-científicos da academia, formando uma nova síntese conhecimentos (CAMACHO, 2018). A luta pelo reconhecimento dos direitos dos camponeses ao acesso a uma educação diferenciada, resultou em conquistas de alguns programas educacionais destinados aos sujeitos do campo que, apesar das dificuldades enfrentadas nos últimos anos, são práticas concretas de Educação do Campo: o Programa Nacional de Educação na Reforma Agrária (PRONERA) e o Programa de Apoio às Licenciaturas em Educação do Campo (PROCAMPO) (FONEC, 2012) ${ }^{1}$.

Com relação a conquista do direito à Educação do Campo, em síntese, fazem parte da fundamentação legal:

1. a Constituição da República Federativa do Brasil, notadamente nos Art. 205,206 e 207 ;

2. o Plano Nacional de Educação - Lei n. ${ }^{\circ}$ 10.172, de 09/01/2001;

3. a Lei de Diretrizes e Bases da Educação Nacional (Lei n. ${ }^{\circ}$ 9.394, de 20/12/1996), regulamentada pelo Decreto n. ${ }^{\circ}$ 2.208, de 17 de abril de 1997;

4. o Decreto 7.352/2010, de 04 de novembro de 2010, que "Dispõe sobre a política de Educação do Campo e o Programa Nacional de Educação na Reforma Agrária", art. 11-18;

5. as Resoluções do Conselho Nacional de Educação relativas às normas para o Ensino Superior no Brasil, normas para os cursos Técnicos de Nível Médio e Graduação Tecnológica;

6. a Resolução CNE/CEB n. ${ }^{\circ}$ 01/2002 - Diretrizes Operacionais para a Educação Básica nas Escolas do Campo;

7. a Resolução CNE/CEB n. ${ }^{\circ}$ 01/2006 - relativo à Pedagogia da Alternância

\footnotetext{
${ }^{1}$ Neste texto, vamos discutir apenas o PRONERA E O PROCAMPO, apesar de termos outras conquistas como: o Programa Saberes da Terra e o Programa de Iniciação à Docência (PIBID) Diversidade/CAPES etc.
} 
8. o Plano Nacional de Educação para o decênio 2011-2020 (PNE 2011/2020).

Com relação à metodologia da pesquisa, este texto contém um conjunto de discussões presentes na tese de doutorado: "Paradigmas em Disputa na Educação do Campo", mas também conta com avanços de reflexões que foram realizadas desde a defesa da tese. Em nosso debate demos ênfase às conquistas de direito à Educação do Campo desde o governo Fernando Henrique Cardoso (FHC) até os governos Petistas, sendo que, também, mencionamos os retrocessos que sofremos a partir do Golpe de Estado (midiático-empresarial-jurídico-parlamentar) de 2016, do governo Temer, até o maior retrocesso sofrido pela história da Educação do Campo no governo Bolsonaro.

A metodologia é dividida em duas partes principais. A primeira é a análise da legislação e de documentos oficiais relativos à Educação do Campo. A segunda está relacionada com a entrevista de alguns camponeses-assentados que eram estudantes do Curso Especial de Geografia do Pronera (CEGeo) ${ }^{2}$.

A entrevista ocorreu por meio de questionário semiestruturado em que gravamos e transcrevemos suas narrativas. Os entrevistados eram militantes dos movimentos socioterritoriais camponeses ligados a Via Campesina: MST, MPA, MAB, MMC e PJR.

\section{Da Educação Rural à Educação como "Direito de Todos" e "Dever do Estado": uma análise Histórica das Constituições Brasileiras}

De acordo com o que diz o texto das Diretrizes Operacionais para a Educação Básica das Escolas do Campo, nos textos constitucionais sempre foi dado um tratamento periférico para a educação escolar do campo. Ela sempre foi pensada como um elemento residual. Essa situação somente foi alterada com a participação dos movimentos socioterritoriais do campo. Um exemplo claro deste processo é a realização da Conferência Nacional Por uma Educação Básica do Campo que teve como objetivo mudar a forma como o campo e a Educação do Campo foi tratada historicamente no Brasil.

\footnotetext{
${ }^{2}$ Foi organizado a partir de uma parceria construída entre a Via Campesina - Brasil; a Escola Nacional Florestan Fernandes (ENFF); a Faculdade de Ciências e Tecnologia da Universidade Estadual Paulista Júlio Mesquita Filho (UNESP) - Campus de Presidente Prudente; o Ministério do Desenvolvimento Agrário (MDA) e Instituto Nacional de Colonização e Reforma Agrária (INCRA) por meio do Programa Nacional de Educação na Reforma Agrária (PRONERA).
}

CAMPO-TERRITÓRIO: revista de geografia agrária, v. 15, n. 38, p. 81-105, dez., 2020 
[...] há que se registrar na abordagem dada pela maioria dos textos constitucionais, um tratamento periférico da educação escolar do campo. É uma perspectiva residual e condizente, salvo conjunturas específicas, com interesses de grupos hegemônicos na sociedade. As alterações nesta tendência, quando identificadas, decorrem da presença dos movimentos sociais do campo no cenário nacional. É dessa forma que se pode explicar a realização da Conferência Nacional Por uma Educação Básica do Campo, que teve como principal mérito recolocar, sob outras bases, o rural, e a educação que a ele se vincula. (BRASIL, 2002, p. 11).

Apesar das características agrárias do Brasil, a proposta de uma educação para meio rural não havia feito parte ainda dos textos constitucionais de 1824 e 1891. Este fato evidencia duas questões. Primeiro, o descaso dos dirigentes para com a Educação do Campo. Segundo, os resquícios de matrizes culturais hegemônicas que tem como núcleo central uma economia agrária baseada no latifúndio e no trabalho escravo (BRASIL, 2002).

A introdução da educação rural no ordenamento jurídico brasileiro só apareceu em 1923, nos anais do $1^{\circ}$. Congresso de Agricultura do Nordeste Brasileiro. Todavia, o modelo de educação rural pensado na época, era um modelo patronal, mais uma forma de dominação das elites sobre os povos do campo. Educação domesticadora, que tinha o objetivo de realizar um controle sociopolítico sobre as classes subalternas (FERNANDES, 2004). A introdução da educação rural no ordenamento jurídico está relacionada com o fato de que era necessário buscar formas de conter o movimento migratório e elevar a produtividade no campo.

[...] a introdução da educação rural no ordenamento jurídico brasileiro remete às primeiras décadas do século $\mathrm{XX}$, incorporando, no período, o intenso debate que se processava no seio da sociedade a respeito da importância da educação para conter o movimento migratório e elevar a produtividade no campo. A preocupação das diferentes forças econômicas, sociais e políticas com as significativas alterações constatadas no comportamento migratório da população foi claramente registrada nos anais dos Seminários e Congressos Rurais realizados naquele período.

É do $1^{\circ}$ Congresso da Agricultura do Nordeste Brasileiro - 1923, por exemplo, o registro da importância dos Patronatos na pauta das questões agrícolas que deveriam ser cuidadosamente estudadas. (BRASIL, 2002, p. 5, grifo nosso).

Somente na constituição de 1934 é que, pela primeira vez, aparece uma referência à educação rural. Porém, ainda, se constituía a partir de um modelo de dominação da elite latifundiária (FERNANDES, 2004). É marcada pelas ideias do 

pelo direito à Educação do Campo

Movimento Renovador e pelo Manifesto dos Pioneiros da Educação Nova ${ }^{3}$. É produto de uma nova correlação de forças da sociedade daquele período formada a partir da insatisfação de algumas parcelas da sociedade: cafeicultores, intelectuais, classes médias e, até mesmo, as massas populares urbanas. Neste período, têm-se profundas reformas educacionais que abrangiam as relações entre as instituições de ensino e a sociedade (BRASIL, 2002).

Com relação às constituições de 1937 e 1946 temos como destaque a mudança de poder da elite agrária para as emergentes elites industriais. Neste período, o modelo de educação rural é mantido, todavia, implanta-se o ensino agrícola sob o controle do patronato, intensificando o sistema de subjugação dos trabalhadores ao capital (FERNANDES, 2004).

Na constituição de 10 de dezembro de 1937 temos a inserção da educação profissional devido ao contexto de industrialização nascente no Brasil. Esta modalidade de ensino era destinada às classes menos favorecidas e era considerada como um dever, primordialmente, do Estado que deveria fundar seus institutos de ensino profissional e subsidiar as iniciativas privadas. Este sistema legitimou as desigualdades e não trouxe proposições para o ensino agrícola.

Em 10 de dezembro de 1937, é decretada a Constituição que sinaliza para a importância da educação profissional no contexto da indústria nascente. Esta modalidade de ensino, destinada às classes menos favorecidas, é considerada, em primeiro lugar, dever do Estado, o qual, para executá-lo, deverá fundar institutos de ensino profissional e subsidiar os de iniciativa privada e de outras esferas administrativas. Essa inovação, além de legitimar as desigualdades sociais nas entranhas do sistema de ensino, não se faz acompanhar de proposições para o ensino agrícola. (BRASIL, 2002, p. 7).

Na Constituição de 1946, com relação à educação, ocorre um processo de descentralização sem desresponsabilizar a União pelo atendimento escolar. É assegurado a gratuidade do ensino primário. O texto também retoma o incremento ao ensino na zona rural, mas diferentemente da Constituição de 1934, transfere à empresa privada, inclusive às agrícolas, a responsabilidade pelo custeio desse incremento. No inciso III, do art. 168,

\footnotetext{
${ }^{3}$ O lançamento do Manifesto foi em março do ano de 1932, sendo resultado da IV Conferência Nacional de Educação no ano de 1931, com o tema geral "As grandes diretrizes da educação popular". O Manifesto representou um marco na renovação educacional do Brasil. Os pioneiros assumiram a missão de conduzir o Brasil à Modernidade pela via da Educação. O Manifesto dos Pioneiros veio legitimar um grupo de intelectuais da educação que visavam salvar o país do seu atraso e levá-lo a modernização por meio da educação, sendo eles os agentes ou heróis dessa mudança (VIEIRA, 2020).
} 

pelo direito à Educação do Campo

está determinada que um dos princípios a ser seguido pela legislação de ensino é a responsabilidade das empresas com a educação: "III - as empresas industriais, comerciais e agrícolas, em que trabalham mais de cem pessoas, são obrigadas a manter ensino primário gratuito para os seus servidores e para os filhos destes”. (BRASIL, 2002, p. 9).

As constituições de 1967 e a emenda de 1969 são produtos da época da ditadura militar. Sendo assim, não há mudanças desse modelo hegemônico de subalternidade na educação para com as populações do campo (FERNANDES, 2004). De acordo com o parecer n 36/2001 (BRASIL, 2002), na Constituição de 1967, temos a obrigatoriedade de as empresas convencionais agrícolas e industriais oferecerem, o ensino primário gratuito de seus empregados e dos filhos destes. Em 1969, promulgada a emenda à Constituição de 24 de janeiro de 1967, temos a obrigatoriedade das empresas, inclusive das agrícolas, com o ensino primário gratuito dos filhos dos empregados, entre os sete e quatorze anos.

É somente na Constituição atual de 1988 que a educação é promulgada como direito de todos. Nascia, então, nesta constituição a possibilidade de construção de uma Educação do Campo livre do julgo das elites (FERNANDES, 2004). O fato de a constituição de 1988 proclamar a educação com um direito de todos e dever do Estado, estende a obrigatoriedade a Educação do Campo, também.

Quanto ao texto da Carta de 1988, pode-se afirmar que proclama a educação como direito de todos e, dever do Estado, transformando-a em direito público subjetivo, independentemente dos cidadãos residirem nas áreas urbanas ou rurais. Deste modo, os princípios e preceitos constitucionais da educação abrangem todos os níveis e modalidades de ensino ministradas em qualquer parte do país.

Assim sendo, apesar de não se referir direta e especificamente ao ensino rural no corpo da Carta, possibilitou às Constituições Estaduais e à Lei de Diretrizes e Bases da Educação Nacional - LDB - o tratamento da educação rural no âmbito do direito à igualdade e do respeito às diferenças. (BRASIL, 2002, p. 10, grifo nosso).

No artigo 206, reforça-se o aspecto inclusivo constitucional que interpreta a educação enquanto um direito de todos e, também, afirma a necessidade da igualdade de condições de acesso a mesma, complementada no artigo 208 que se refere ao dever do Estado para com a educação (PRUDENTE, 2020). Assim, tendo como base a Constituição de 1988 - Capítulo III: Da Educação, Da Cultura e Do Desporto - Seção I: Da Educação, nos artigos 205, 206 e 208 - podemos dizer que a mesma assegura que a Educação Básica é um direito de todos, é obrigatória e gratuita. É um dever do Estado em 
ofertá-la, com igualdade de acesso e permanência. Vejamos o que diz o texto da

Constituição Federal de 1988:

Art.205 - A educação, direito de todos e dever do Estado e da família, será promovida e incentivada com a colaboração da sociedade, visando ao pleno desenvolvimento da pessoa, seu preparo para o exercício da cidadania e sua qualificação para o trabalho.

Art.206 - O ensino será ministrado com base nos seguintes princípios: I - igualdade de condições para o acesso e permanência na escola; [...]. Art. 208 - O dever do Estado com a educação será efetivado mediante a garantia de:

I - educação básica obrigatória e gratuita dos 4 (quatro) aos 17 (dezessete) anos de idade, assegurada inclusive sua oferta gratuita para todos os que a ela não tiveram acesso na idade própria; [...].

O Direito à educação, em todos os níveis, deve contemplar quatro características: disponibilidade, acessibilidade material e acessibilidade econômica, aceitabilidade e adaptabilidade.

Disponibilidade - significa que a educação gratuita deve estar à disposição de todas as pessoas. A primeira obrigação do Estado brasileiro é assegurar que existam escolas de ensino fundamental para todas as pessoas.

Acessibilidade - é a garantia de acesso à educação pública disponível, sem qualquer tipo de discriminação. A não discriminação é um dos princípios primordiais das normas internacionais de direitos humanos e se aplica a todos os direitos. A não discriminação deve ser de aplicação imediata e plena.

Aceitabilidade - é a garantia da qualidade da educação, relacionada aos programas de estudos, aos métodos pedagógicos e à qualificação dos(as) professores(as).

Adaptabilidade - requer que a escola se adapte a seus alunos e alunas e que a educação corresponda à realidade imediata das pessoas respeitando sua cultura, costumes, religião e diferenças -, assim como às realidades mundiais, em rápida evolução. (HADAD, 2012, p. 219).

Desta forma, mesmo não aparecendo no corpo do texto referência a Educação do Campo, ela propiciou que fosse elaborada a especificidade desta modalidade de educação na Lei de Diretrizes e Bases da Educação Nacional (LDB) com base nos princípios do direito à igualdade e do respeito às diferenças. 


\section{A transição da Educação Rural para a Educação do Campo na Lei de Diretrizes e} Bases da Educação Nacional (LDB)

A primeira grande conquista para a Educação do Campo diz respeito à aprovação do texto final da $L D B$ - Lei de Diretrizes e Bases da Educação Nacional - (Lei $n^{\circ}$ 9.394, de 20 de dezembro de 1996). Neste texto, mesmo com a terminologia antiga de educação rural, foi introduzido um artigo específico para tratar esta questão (NASCIMENTO, 2003).

De acordo com a LDB (Lei de Diretrizes e Bases da Educação Nacional), em seu artigo 28, na educação básica promovida para as populações rurais os sistemas de ensino deverão se adaptar as especificidades da vida rural a partir de cada região. Estas adaptações que atenda às necessidades dos espaços rurais referem-se aos conteúdos curriculares e metodologias, ao calendário adaptado aos ciclos agrícolas e condições climáticas e às características do trabalho rural. Vejamos o que diz a LDB:

\footnotetext{
$\mathrm{Na}$ oferta de educação básica para a população rural, os sistemas de ensino promoverão as adaptações necessárias à sua adequação às peculiaridades da vida rural e de cada região, especialmente:

I - conteúdos curriculares e metodologias apropriadas às reais necessidades e interesses da zona rural;

II - organização escolar própria, incluindo adequação do calendário escolar, às fases do ciclo agrícola e às condições climáticas;

III - adequação a natureza do trabalho rural. (grifo nosso).
}

A Lei de Diretrizes e Bases da Educação Nacional traz uma inovação que é a noção de adaptação, ou seja, a adequação da educação aos interesses de seus sujeitos em sujas respectivas realidades. É o reconhecimento da diversidade sociocultural, do direito a pluralidade, possibilitando a elaboração de diferentes diretrizes operacionais (FERNANDES, 2004).

A criação de conteúdos curriculares e de metodologias adequadas à realidade das populações rurais significa que o que vai ser ensinado em sala de aula deve partir da realidade na qual o educando está inserido. É uma educação contextualizada espacial e historicamente. No caso dos educandos que participam dos movimentos sociais, a inserção dessa realidade em sala de aula passa a ser garantida legalmente. Isto quer dizer que os sistemas de educação, em sua maioria municipal e estadual, que negam a participação dos movimentos socioterritoriais na escola, estão desrespeitando a legislação vigente específica sobre a Educação do Campo. 
Os conteúdos que tragam a sua realidade para a sala de aula e o seu histórico de lutas para a conquista da terra, no caso dos camponeses assentados, fazem com que os estudantes-camponeses valorizem o seu modo de vida. Ao contrário da educação urbana e neoliberal que disseminam a ideologia de que a urbanização e o agronegócio é a única forma de progresso existente. Com esta perspectiva, a escola desestimulará os estudantescamponeses do seu modo de vida ao mesmo tempo em que apresenta a cidade como superior e o lugar ideal para viver, morar, trabalhar, estudar, consumir etc.

Algumas disciplinas específicas que auxiliem na organização da produção da propriedade, desde o cultivo do solo até a comercialização da produção são itens que podem ser elencados entre os direitos conquistados por este inciso do artigo 28 da LDB.

A metodologia da Pedagogia da Alternância é um importante instrumento de ensino-aprendizagem para adequar a educação a realidade dos educandos do campo. Sua utilização é garantida pela LDB, tendo em vista que a mesma se enquadra no requisito a respeito da necessidade de adequação do calendário escolar aos ciclos agrícolas (períodos do plantio e da colheita) e as condições climáticas (períodos de secas e de cheias).

A importância desse item da lei que versa acerca da necessidade de um calendário específico para os sistemas de ensino nas áreas rurais está relacionada a uma questão fundamental que é a existência de uma enorme diferença entre as formas de produzir no campo e na cidade. A produção no campo depende do respeito aos ciclos naturais de plantio e de colheita, não dá para artificializar esta condição. Por mais mudanças técnicas que tenhamos, existe uma condição natural a ser respeitada na produção agrícola. Isto significa que o trabalho agrícola é sazonal. Partindo dessa premissa, escolas no campo e escolas na cidade não devem acompanhar o mesmo calendário.

Tendo em vista que uma das razões na qual se fundamenta a necessidade da Educação do Campo é o modo de vida camponês, inerente a esta questão dos ciclos naturais de plantio e colheita está o modo de vida camponês. Pois, o trabalho familiar camponês possui uma dinâmica própria de produção que exige que os filhos ajudem no trabalho no período do plantio e da colheita. Então, quando temos um calendário escolar que não respeita esta especificidade, os resultados são bastante negativos.

Segundo Luiz Carlos Batista (1995) o fato de os pais necessitarem dos filhos nas safras, faz com que eles os retiram da escola neste período. O estudante-camponês é, inevitavelmente, solicitado para cumprir esta necessidade econômica específica dos 
camponeses. O balanço trabalho-consumo é uma regra inerente à condição camponesa. No entanto, este se torna um dos itens causadores da evasão escolar no campo. Daí, a necessidade de um calendário específico diferente do calendário urbano. Não temos que fazer o modo de vida camponês se adaptar ao calendário da educação urbana, mas o contrário, os sistemas de educação é que devem se adaptar ao modo de vida camponês. Como temos uma lei que permite esta adaptação, ela tem que ser cumprida.

A adaptação a esta condição específica camponesa está interligada com o terceiro item do artigo 28 da LDB, qual seja a "adequação a natureza do trabalho rural". A característica particular do trabalho e da cultura camponesa requer a aprendizagem de conteúdos e metodologias específicas, além de calendários adaptados. São três itens que se inter-relacionam mutuamente.

Todavia, apesar das conquistas que trouxe a LDB com relação à Educação do Campo, como explicamos, temos ainda algumas limitações na prática. As responsabilidades da educação em nível Fundamental são divididas. Nesta divisão, cabe ao município a responsabilidade do Ensino Fundamental nos anos iniciais. Mas, um grande número, ainda, de secretarias municipais desconsidera o processo de resistência cultural e política do campesinato como importante elemento do processo educativo e optam em transportar os estudantes do campo para a cidade. São viagens, na maioria das vezes, cansativas que acabam desestimulando o educando a aprender. Pois, o estudante, além de trabalhar com a família, ainda tem que enfrentar a jornada da viagem para a escola (CAMACHO, 2008, 2014).

As secretarias municipais optam pelo transporte ao invés da instalação das escolas no campo porque encontram uma facilidade maior de organização e um gasto financeiro menor. Com o escreve Ademar Bogo:

Da roça já nem se fala

É demais a crueldade

Ao invés de fazer escolas

Levam os jovens pra cidade.

Dizem que é mais barato

Levar as crianças do mato

Isto é de sul a norte.

Eles não estão falando

Mas com isto estão criando

A indústria do transporte ${ }^{4}$.

${ }^{4}$ Poesia: Relíquias da Educação.

CAMPO-TERRITÓRIO: revista de geografia agrária, v. 15, n. 38, p. 81-105, dez., 2020 
Todavia, ao concentrarem todos os educandos do município na cidade, negam o direito desses estudantes as especificidades territoriais-educacionais garantidas pela lei. Mas, não é apenas isso. Ao negar esta especificidade nega-se, concomitantemente, a possibilidade de construção de uma identidade territorial e de classe camponesa, essencial para a produção/reprodução dos territórios camponeses. Esta é a velha prática educacional domesticadora que se contrapõe a proposta de Educação do Campo emancipatória (NASCIMENTO, 2003; CAMACHO, 2008, 2014).

\section{A Educação do Campo a partir das Diretrizes Operacionais para a Educação Básica das Escolas do Campo}

Não vou sair do campo Pra poder ir pra escola

Educação do campo

É direito e não esmola

O povo camponês

$O$ homem e a mulher

O negro quilombola

Com seu canto de afoxé

Ticuna, Caeté

Castanheiros, seringueiros

Pescadores, posseiros

Nesta luta estão de pé

Cultura e produção

Sujeitos da cultura

Nossa agricultura

Pro bem da população

Construir soberania

Pra viver o novo dia

Com mais humanização.

Quem vive na floresta

Dos rios e dos mares

De todos os lugares

Onde o sol faz uma fresta Quem a sua força empresta Nos quilombos nas aldeias

E quem na terra semeia

Venha aqui fazer a festa

Gilvan Santos ${ }^{5}$

\footnotetext{
${ }^{5}$ Música: Não vou sair do campo. Cantares da Educação do Campo.
} 

pelo direito à Educação do Campo

Depois da LDB, a segunda grande conquista foi a aprovação das Diretrizes Operacionais para a Educação Básica das Escolas do Campo (Parecer n 36/2001 e Resolução 1/2002 do Conselho Nacional de Educação). Esta é a primeira legislação específica criada para a Educação do Campo. Ela traz novas possibilidades para que a esfera da educação seja incorporada com suas particularidades ao Sistema Público de Ensino. Com relação às Diretrizes Operacionais para a Educação Básica das Escolas do Campo (Parecer nº 36/2001 e Resolução 1/2002 do Conselho Nacional de Educação), aprovadas em 2001 pelo Conselho Nacional de Educação, podemos dizer que elas representam “[...] um avanço real para a Educação Básica do Campo. Da mesma forma, o parecer da relatora está repleto de considerações bem fundamentadas na história da educação e no reconhecimento dos seus principais protagonistas". (FERNADES, 2004, p. 144).

Segundo Antonio Munarim, a Resolução CNE/CEB n 1, de 03 abril de 2002, que institui as "Diretrizes Operacionais da Educação Básica para as Escolas do Campo", mesmo com algumas fragilidades de conteúdo, foi uma grande conquista dos sujeitos do campo. As diretrizes marcam um ponto de encontro entre o Estado e sociedade. Elas definem a responsabilidade que o Estado tem em garantir o acesso à educação das classes subalternas respeitando sua diversidade cultural e, concomitantemente, diminuindo as desigualdades. Em suas palavras:

[...] as Diretrizes Operacionais significam um ponto de inflexão nessa relação Estado-Sociedade na medida em que consolidam e materializam direitos. A Resolução faz indicações concretas de responsabilidades dos entes estatais e de como se deve cumprir o direito à educação em se tratando de populações socialmente desiguais e culturalmente diversas. Mais que um eventual "ponto de encontro" entre Estado e Sociedade, que, neste caso, implicaria uma visão dicotômica dessa relação, as Diretrizes Operacionais têm o significado de construção democrática na forma de ampliação do Estado como espaço, por excelência, da política. (2006, p. 18).

Neste sentido, podemos destacar as seguintes conquistas do documento para a consolidação da Educação do Campo. O texto do documento em seu artigo $2^{\circ}$ explica os objetivos das diretrizes que é o de adequar o projeto institucional das escolas do campo às Diretrizes Curriculares Nacionais da Educação Básica. Vejamos o que diz o documento:

Art. $2^{\circ}$ Estas Diretrizes, com base na legislação educacional, constituem um conjunto de princípios e de procedimentos que visam adequar o 
projeto institucional das escolas do campo às Diretrizes Curriculares Nacionais para a Educação Infantil, o Ensino Fundamental e Médio, a Educação de Jovens e Adultos, a Educação Especial, a Educação Indígena, a Educação Profissional de Nível Técnico e a Formação de Professores em Nível Médio na modalidade Normal. (BRASIL, 2002, p. 22).

Em seguida, o documento menciona o que é a identidade da escola do campo. A escola do campo é identificada enquanto aquela que está vinculada a realidade espacialtemporal dos estudantes. Levando-se em consideração os saberes e a memória coletiva dos mesmos e valorizando o conhecimento produzido pelos movimentos sociais.

Parágrafo único. A identidade da escola do campo é definida pela sua vinculação às questões inerentes à sua realidade, ancorando-se na temporalidade e saberes próprios dos estudantes, na memória coletiva que sinaliza futuros, na rede de ciência e tecnologia disponível na sociedade e nos movimentos sociais em defesa de projetos que associem as soluções exigidas por essas questões à qualidade social da vida coletiva no país. (BRASIL, 2002, p. 22).

Nos artigos 9 e 10 fica claro a defesa do protagonismo dos movimentos sociais, indicando que os mesmos poderão subsidiar políticas educacionais. A proposta é de criação de uma escola que seja resultante da participação da comunidade local, dos movimentos sociais e do sistema de ensino formal.

Art. $9^{\circ}$ As demandas provenientes dos movimentos sociais poderão subsidiar os componentes estruturantes das políticas educacionais, respeitado o direito à educação escolar, nos termos da legislação vigente.

Art. $10 \mathrm{O}$ projeto institucional das escolas do campo, considerado o estabelecido no artigo 14 da LDB, garantirá a gestão democrática, constituindo mecanismos que possibilitem estabelecer relações entre a escola, a comunidade local, os movimentos sociais, os órgãos normativos do sistema de ensino e os demais setores da sociedade. (BRASIL, 2002, p. 23).

No Artigo 11, inciso II, há no texto das diretrizes um incentivo para a construção de escolas autônomas que desenvolvam a autogestão: "II - para a abordagem solidária e coletiva dos problemas do campo, estimulando a autogestão no processo de elaboração, desenvolvimento e avaliação das propostas pedagógicas das instituições de ensino". (BRASIL, 2002, p. 24, grifo nosso).

Dentre os marcos legais conquistados merece destaque o Decreto n. ${ }^{\circ} 7.352$, de 04 de novembro de 2010, que elevou a Educação do Campo à condição de política de Estado. Assim, a característica principal desse decreto é o "[...] reconhecimento jurídico 
tanto da universalidade do direito à educação quanto da obrigatoriedade do Estado em promover intervenções que atentem para as especificidades necessárias ao cumprimento e garantia dessa universalidade". (FONEC, 2012, p. 15). Vejamos o que diz o decreto:

Art. 1 A política de educação do campo destina-se à ampliação e qualificação da oferta de educação básica e superior às populações do campo, e será desenvolvida pela União em regime de colaboração com os Estados, o Distrito Federal e os Municípios, de acordo com as diretrizes e metas estabelecidas no Plano Nacional de Educação e o disposto neste Decreto.

O respeito a diversidade do modo de vida e da territorialidade dos sujeitos do campo é, também, outra marca central desse decreto. Entendendo-se por...

I - populações do campo: os agricultores familiares, os extrativistas, os pescadores artesanais, os ribeirinhos, os assentados e acampados da reforma agrária, os trabalhadores assalariados rurais, os quilombolas, os caiçaras, os povos da floresta, os caboclos e outros que produzam suas condições materiais de existência a partir do trabalho no meio rural; e

II - escola do campo: aquela situada em área rural, conforme definida pela Fundação Instituto Brasileiro de Geografia e Estatística - IBGE, ou aquela situada em área urbana, desde que atenda predominantemente a populações do campo. (grifo nosso).

No Artigo $2^{\underline{0}}$ estão os princípios da Educação do Campo:

I - respeito à diversidade do campo em seus aspectos sociais, culturais, ambientais, políticos, econômicos, de gênero, geracional e de raça e etnia;

II - incentivo à formulação de projetos político-pedagógicos específicos para as escolas do campo, estimulando o desenvolvimento das unidades escolares como espaços públicos de investigação e articulação de experiências e estudos direcionados para o desenvolvimento social, economicamente justo e ambientalmente sustentável, em articulação com o mundo do trabalho;

III - desenvolvimento de políticas de formação de profissionais da educação para o atendimento da especificidade das escolas do campo, considerando-se as condições concretas da produção e reprodução social da vida no campo;

IV - valorização da identidade da escola do campo por meio de projetos pedagógicos com conteúdos curriculares e metodologias adequadas às reais necessidades dos alunos do campo, bem como flexibilidade na organização escolar, incluindo adequação do calendário escolar às fases do ciclo agrícola e às condições climáticas; e

$\mathrm{V}$ - controle social da qualidade da educação escolar, mediante a efetiva participação da comunidade e dos movimentos sociais do campo. 
No artigo $3^{\circ}$ tem a afirmação de que o governo federal tem a obrigação de garantir políticas públicas de Educação do Campo:

Art. 3ํㅡㄹ Caberá à União criar e implementar mecanismos que garantam a manutenção e o desenvolvimento da educação do campo nas políticas públicas educacionais, com o objetivo de superar as defasagens históricas de acesso à educação escolar pelas populações do campo.

No artigo 12 estão elencados os objetivos do PRONERA:

I - oferecer educação formal aos jovens e adultos beneficiários do Plano Nacional de Reforma Agrária - PNRA, em todos os níveis de ensino; II - melhorar as condições do acesso à educação do público do PNRA; III - proporcionar melhorias no desenvolvimento dos assentamentos rurais por meio da qualificação do público do PNRA e dos profissionais que desenvolvem atividades educacionais e técnicas nos assentamentos.

A luta por políticas públicas é uma bandeira dos movimentos socioterritoriais estão colocando na pauta dos governos a questão da Educação do Campo. No território das políticas públicas de Educação do Campo, temos o PRONERA. De acordo com o Manual de Operações do PRONERA, o Programa Nacional de Educação na Reforma Agrária é uma política pública de Educação do Campo desenvolvida nas áreas de Reforma Agrária. Seu principal objetivo é fortalecer o meio rural enquanto território de vida em todas as suas dimensões: econômicas, sociais, políticas, culturais e éticas. O Programa nasceu em 1998 da luta das representações dos movimentos sociais e sindicais do campo. A implantação deste programa permitiu que milhares de jovens e adultos, trabalhadores das áreas de Reforma Agrária tenham o direito do acesso a diferentes níveis de ensino (BRASIL, 2011).

Propõe e apoia os projetos de educação voltados para o desenvolvimento das áreas de reforma agrária. O público-alvo são jovens e adultos camponeses oriundos de projetos de assentamento criados e/ou reconhecidos pelo Incra, quilombolas e trabalhadores acampados cadastrados e beneficiários do Programa Nacional de Crédito Fundiário (PNCF). Compreende a ações de alfabetização de jovens e adultos, escolarização nos níveis fundamental, médio, superior e pós-graduação, formação continuada de professores, formação técnico-profissional, produção agropecuária e gestão do empreendimento rural. Todas estas modalidades de educação estão pautadas em metodologias que têm como base a diversidade cultural e socioterritorial, os processos de 
interação e transformação do campo, a gestão democrática e o avanço científico e tecnológico (BRASIL, 2020).

A Segunda Pesquisa Nacional de Educação na Reforma Agrária (II PNERA) foi realizada em parceria com o Instituto Nacional de Estudos e Pesquisa Anísio Teixeira (MEC-INEP) e o Instituto de Pesquisas Aplicadas (IPEA). Teve como objetivo caracterizar a demanda educacional e diagnosticar a situação do ensino ofertado nos assentamentos da Reforma Agrária. O resultado da pesquisa é que no período entre 1998 a 2011 foram realizados 320 cursos do PRONERA por meio de 82 instituições de ensino em todo o país, sendo 167 de Educação de Jovens e Adultos Fundamental, 99 de nível Médio e 54 de nível Superior. Os cursos foram realizados em 880 municípios, em todas as unidades da federação, num total tivemos a formação de 192 mil camponeses e camponesas nos 27 estados da Federação (BRASIL, 2015; CAMACHO, 2018; MST, 2020). Neste processo, tivemos a inclusão de sujeitos sociais do campo marcados historicamente pela exclusão social e ausência de políticas públicas na área da educação.

Sob influência teórica-política-ideológica do PRONERA, se origina o Programa de Apoio à Formação Superior em Licenciatura em Educação do Campo (PROCAMPO). Seu objetivo é o apoio à implantação de cursos regulares de licenciatura em Educação do Campo nas instituições públicas de ensino superior para a formação de educadores para a docência nos anos finais do ensino fundamental e ensino médio em escolas do campo. Surge das demandas apresentadas pelos movimentos sociais e sindicais, no documento final da II Conferência Nacional de Educação do Campo realizada em 2004. O Ministério da Educação (MEC), por meio da Secretaria de Educação Continuada, Alfabetização, Diversidade e Inclusão (Secadi), instituiu, em 2005, um grupo de trabalho composto por representantes dos movimentos sociais e sindicais, das universidades e técnicos do Ministério da Educação para elaborar subsídios a uma política de formação de educadores do campo. Os resultados produzidos neste grupo de trabalho transformaram-se no PROCAMPO (SÁ; MOLINA, 2012; MOLINA; ANTUNES-ROCHA, 2014). A oferta de cursos de licenciatura específicos para a qualificação dos professores do campo começou em 2006, com um projeto-piloto desenvolvido pelas universidades federais de Minas Gerais (UFMG), da Bahia (UFBA), de Sergipe (UFS) e a Universidade de Brasília (UnB) (BRASIL, 2020).

Estes programas são a construção teórico-prática da Educação do Campo. Ele está vinculado ao Movimento da Articulação Nacional por uma Educação do Campo, 
atualmente, Fórum Nacional de Educação do Campo (FONEC). Os dois movimentos fazem parte do mesmo tempo histórico. Funciona como uma espécie de indutor da própria reflexão e de muitas ações da Educação do Campo. O objetivo central é a construção de uma educação adequada à lógica do trabalho e da cultura nos territórios dos povos do campo em busca de outra forma de desenvolvimento (MOLINA, 2004; CAMACHO, 2014). Nesta perspectiva, as universidades e os centros de pesquisa, passam a produzir referenciais teóricos capazes de compreender a nova dinâmica do campo brasileiro (ARROYO; CALDART; MOLINA, 2004).

Outras conquistas da Educação do Campo estão presentes no Plano Nacional de Educação para o decênio 2011-2020 (PNE - 2011/2020). Entre elas podemos citar com relação a "Meta 2: Universalizar o ensino fundamental de nove anos para toda população de 6 a 14 anos". As estratégias:

2.5) Manter programa nacional de reestruturação e aquisição de equipamentos para escolas do campo, bem como de produção de material didático e de formação de professores para a educação do campo, com especial atenção às classes multisseriadas.

2.7) Desenvolver tecnologias pedagógicas que combinem, de maneira articulada, a organização do tempo e das atividades didáticas entre a escola e o ambiente comunitário, em prol da educação do campo e da educação indígena. (grifo nosso).

A questão da Educação do Campo discutida a partir da legislação é uma importante conquista dos movimentos socioterritoriais. Mas, a luta continua, pois não basta estar na legislação, é necessário que se cumpra a lei que confere o respeito às especificidades dos "sistemas de ensino da educação básica para a população rural" (termos utilizados na LDB). Dessa forma, as políticas públicas podem ser um importante instrumento de transformação social a partir da educação.

[...] Outra conquista importante está sendo à entrada da Questão da Educação do Campo na agenda de luta e de trabalho de um número cada vez maior de movimentos sociais $e$ sindicais de trabalhadores $e$ trabalhadoras do campo, o que vem pressionando sua inclusão na agenda de alguns governos municipais, estaduais e também na agenda do governo federal. (CALDART, 2005, p. 1, grifo nosso).

Neste sentido, atualmente, a Educação do Campo vem conquistando seu espaço na agenda dos movimentos socioterritoriais camponeses; na universidade: em espaços de diálogos de eventos científicos, projetos de pesquisa e extensão, trabalhos de conclusão 
de curso, dissertação de mestrado e teses de doutorado sobre ao assunto; nas escolas do campo; nos cursos de formação de professores; na legislação; nas políticas públicas etc.

\section{A Luta pelo Direito à Educação do Campo Continua...}

Todavia, apesar das conquistas alcançadas pelos movimentos camponeses no que concerne à Educação do Campo, elas não chegaram a todos os lugares com a mesma intensidade. De acordo com Cds, o MST luta no estado de São Paulo para conquistar o direito de ter uma educação que respeite a realidade dos educandos-assentados, pois a proposta de educação pública estadual não inclui a realização de um ensino que respeite as especificidades dos estudantes-camponeses-assentados. Ainda continua sendo aplicado os mesmos conteúdos e metodologias dos grandes centros urbanos nas escolas dos assentamentos.

A nossa luta também nos assentamentos e nos acampamentos é por uma experiência de Educação do Campo, mas nós sabemos que, principalmente, aqui em São Paulo é uma proposta de educação do governador Serra, ela é homogênea, ela não respeita a realidade das famílias, porque o mesmo conteúdo, a mesma metodologia que é utilizada nos grandes centros, como a cidade de São Paulo, é utilizada nas cidades do interior e é utilizada nas escolas dos assentamentos. Então, o governo quer dominar, quer controlar o conhecimento da população aqui no Estado de São Paulo. A nossa luta é por uma educação que respeita as experiências [dos movimentos sociais] [...]. (Cds, ENFF, Jul. 2010).

De acordo com GM, militante do MST e estudante do CEGeo, há de se tomar muito cuidado quando afirmamos que determinada experiência pode ser considerada como Educação do Campo. Pois, podemos cair em um modismo e toda educação praticada no campo virar sinônimo de Educação do Campo. Estas experiências devem ser mais bem analisadas na perspectiva dos princípios político-ideológicos que compõem estas experiências.

E aí virou muito assim, todo mundo, é muito bonito falar Educação do Campo, o governo ele começa a pregar essas coisas e aí vira muito banal, de qualquer forma a educação, diz que é, mas não é, tem que ter muito cuidado quando se fala nessa Educação do Campo, vai ser algo bem mais amplo, diferente. Muitas vezes, a gente até se pergunta se a nossa escola itinerante tá mesmo fazendo Educação do Campo ou nós estamos só, no diz que é Educação do Campo, mas na prática não faz, tem muitas dessas questões. (GM, ENFF, Jul. 2010). 
Ainda, segundo Jsf, militante da Pastoral da Juventude Rural e educanda do CEGeo, existem muitas escolas que dizem que trabalham na perspectiva da Educação do Campo, mas não é isso que enxergamos na prática.

[...] As escolas do campo, que estão no campo, ainda carregam consigo as grades curriculares da cidade [...] não se modificou nada, então parece ser uma tortura. Então, não basta apenas assim "a nossa escola trabalha com a proposta de Educação do Campo" se a grade curricular é a mesma tal qual da cidade. Então não é a Educação do Campo. [...]. Então, o desafio maior hoje é nas escolas tradicionais que não tá ligada ao Movimento, às organizações do campo, é organizar o currículo de forma diferenciada. [...]. E aí ainda não conseguimos fazer isso. (Jsf, UNESP, Jan. 2011).

Apesar dos avanços conquistados pela lei, é necessário termos a convicção de que a luta continua, pois sem a luta as leis não se materializam. É preciso acreditarmos na mudança como uma condição fundamental. Nas palavras de Bernardo Mançano Fernandes:

[...] Por essa razão, sem a organização dos povos do campo, as Diretrizes correntes correm o risco de ser letra morta no papel. É fundamental que os sujeitos que construíram as condições para que tivéssemos essas Diretrizes continuem a acreditar que mudar é difícil, mas é possível, como afirma Paulo Freire [...]. (2004, p. 144).

A luta dos sujeitos do campo fez com que suas demandas se materializassem em políticas públicas de Educação do Campo. Sendo que "[...] o argumento jurídico que sustenta a legitimidade dessas políticas é exatamente o fato de caber ao Estado a obrigação de considerar as consequências decorrentes de diferenças e desigualdades históricas quanto ao acesso a tais direitos". (FONEC, 2012, p. 10).

Todavia, é necessário salientarmos quais foram os efeitos do Golpe midiáticoempresarial-jurídico-parlamentar para as políticas de Educação do Campo. De acordo com o Fórum Nacional de Educação do Campo (FONEC, 2017), o orçamento no ano de 2017 para o PRONERA foi o menor da história do Programa, se igualando ao orçamento do governo FHC. A Coordenação do Programa apresenta soluções pela via do financiamento privado, por meio de parcerias com grandes empresas rompendo com a cultura histórica do PRONERA e com sua própria razão de existir, uma política pública financiada com orçamento público, propiciando o acesso dos/as camponeses/as à educação pública. 
O maior retrocesso que tivemos desde a criação do PRONERA foi o Decreto 10.252/2020, publicado pelo governo Bolsonaro, em fevereiro de 2020, que fez uma alteração na estrutura do INCRA, que enfraqueceu o PRONERA. Foi extinto a Coordenação-Geral de Educação do Campo e cidadania inviabilizando a continuidade do PRONERA (GOULD, 2020; MST, 2020).

No Brasil, não se atingiu a universalização da oferta pública da educação formal, pois ainda há limites na sua acessibilidade, em virtude das condições de renda, raça e local de moradia. Há, também, pouca aceitabilidade e adaptabilidade nos serviços ofertados (HADAD, 2012). Isto quer dizer que mesmo com a constituição, a lei não se aplica sem luta. A conquista de avanços na Educação do Campo só é possível devido a forma como os movimentos camponeses organizam-se e conquistam diversos direitos, historicamente excluídos, entre estes, a educação.

Por isso, é necessário termos uma agenda permanente de luta pela Educação do Campo, incluindo: a luta contra o analfabetismo; pelo direito à educação em todos os níveis; pela construção de escolas no campo e pela formação de educadores para atuarem pela transformação político-pedagógica escolas do campo.

\section{Considerações Finais}

Mesmo que a relação entre Estado/universidade/movimentos sociais, que engendra a Educação do Campo, seja permeada de tensionamentos, podemos afirmar que a mesma auxilia como instrumento de resistência de resistência política-culturalterritorial camponesa.

Notamos a dinâmica educativa produzida na luta sociopolítica pela conquista e/ou resistência da/na terra/território. Esta é a práxis da formação humana. Os camponeses vão transformando a realidade e, dialeticamente, autotransformando-se em sujeitos sociais: Sem Terra, classe camponesa, mas, sobretudo, como ser humano, ao mesmo tempo em que os movimentos camponeses se transformam em sujeitos educativos.

$\mathrm{O}$ acesso e a respectiva equidade à educação sempre foi um direito negado para as classes subalternas no campo, por isso, as políticas públicas de Educação do Campo em nível básico ou superior, como o PRONERA e o PROCAMPO, são a oportunidade para a classe camponesa ter acesso ao conhecimento técnico - científico acumulado pela 
humanidade, mesmo tendo a consciência de que esta não é a única forma de conhecimento existente (CAMACHO, 2018).

Desta forma, a transformação do debate da Educação do Campo em políticas públicas, a partir da legislação vigente, nos remete a considerar este fato como sendo a materialização do paradigma da Educação do Campo na sociedade. Fato este possível devido a luta do campesinato em conjunto com intelectuais-militantes que auxiliam na territorialização do Paradigma da Educação do Campo desde a academia às escolas no campo. Todavia, apesar das conquistas, a luta continua...

\section{REFERÊNCIAS}

ANDRADE, Márcia Regina; DI PIERRO, Maria Clara. A construção de uma política de educação na reforma agrária. In: ANDRADE, Marcia Regina; PIERRÔ, Maria Clara Di; MOLINA, Mônica Castagna; JESUS, Sonia Meire Santos Azevedo de et al (Orgs.). A educação na Reforma Agrária em perspectiva. São Paulo: Ação Educativa; Brasília: PRONERA, 2004. p. 19-54.

ARROYO, Miguel G.; CALDART, Roseli S.; MOLINA, Mônica C. Apresentação. In: (org.). Por uma educação do campo. Petrópolis: Vozes, 2004. p. 7-18.

BATISTA, Luiz Carlos. Cadernos de formação: uma contribuição à formação do professor de geografia e a sua atuação em zona rural. Aquidauana: UFMS, 1995.

BRASIL. Câmara de Educação Básica do Conselho Nacional de Educação. Diretrizes Operacionais para Educação Básica nas escolas do campo. Parecer CNE/CEB n ${ }^{\circ}$ 36/2001, 04 dez. 2001. Resolução CNE/CEB 1, de 3 de abril de 2002. Institui Diretrizes Operacionais para a Educação Básica nas Escolas do Campo. In: KOLLING, Edgar Jorge; CÉRIOLI, Paulo Ricardo, OSFS; CALDART, Roseli Salete (Orgs.). Educação do Campo: identidade e políticas públicas. Brasília, DF: articulação nacional Por Uma Educação do Campo, 2002. (Coleção Por Uma Educação do Campo, 4). p. 32-55.

BRASIL. Decreto $n^{\mathbf{0}}$ 7.352, de 4 de novembro de 2010. Dispõe sobre a política de educação do campo e o Programa Nacional de Educação na Reforma Agrária PRONERA. Brasília, DF, 2010.

BRASIL. INCRA. Programa Nacional de Educação na Reforma Agrária (Pronera). Disponível em: <http://www.incra.gov.br/pt/programas-e-acoes-categoria/96-programanacional-de-educacao-na-reforma-agraria-pronera.html>. Acesso em: 1 abr. 2020.

BRASIL. Lei de Diretrizes e Bases Educação Nacional. Lei n. 9394/96, Brasília, DF: MEC. Disponível em: <http://www.planalto.gov.br/ccivil_03/leis/19394.htm>. Acesso em: 06 jul. 2012.

BRASIL. Ministério da Educação. Conselho Nacional de Educação. Câmara De Educação Básica. Diretrizes Operacionais para a Educação Básica nas Escolas do 

pelo direito à Educação do Campo

Campo. Parecer n. ${ }^{\circ}$ 36/2001. Institui Diretrizes Operacionais para a Educação Básica nas Escolas do Campo. Brasília, 2001.

BRASIL. Ministério da Educação. Portal do MEC. Programa de Apoio à Formação Superior em Licenciatura em Educação do Campo (Procampo). Disponível em: <http://portal.mec.gov.br/tv-mec>. Acesso em: 1 abr. 2020.

BRASIL. Ministério da Educação. Referências para uma política nacional de Educação do Campo: cadernos de subsídios. Brasília: MEC/Grupo permanente de trabalho de Educação do Campo, 2004.

BRASIL. Ministério do Desenvolvimento Agrário - MDA. Instituto Nacional de Colonização e Reforma Agrária - INCRA. Programa Nacional de Educação na Reforma Agrária (PRONERA). Manual de Operações do Pronera. Brasília: MDA/INCRA, 2011.

BRASIL. PNE. Plano Nacionalde Educação para o decênio 2011-2020. Brasília, DF: MEC, 2011.

CAMACHO, Rodrigo Simão. O ensino da geografia e a questão agrária nas séries iniciais do ensino fundamental. 2008. 462 f. Dissertação (Mestrado em Geografia) Universidade Federal de Mato Grosso do Sul, Aquidauana, 2008.

CAMACHO, Rodrigo Simão. Os movimentos socioterritoriais camponeses como sujeitos coletivos educativos: trajetórias dos camponeses-militantes no PRONERA/CEGEO In: COLELHO, Fabiano; CAMACHO, Rodrigo Simão. O campo no Brasil contemporâneo: do governo FHC aos governos Petistas (Protagonistas da/na Luta pela Terra/Território e das Políticas Públicas - Vol. II). Curitiba: CRV, 2018. v.2, p. 301-340.

CAMACHO, Rodrigo Simão. Paradigmas em disputa na educação do campo. 2014. 806 p. Tese (Doutorado em Geografia) - Faculdade de Ciências e Tecnologia, Universidade Estadual Paulista, Presidente Prudente, 2014. Disponível em: <http://www2.fct.unesp.br/pos/geo/dis_teses/14/dr/rodrigo_camacho.pdf>.

CAMACHO, Rodrigo Simão. Políticas Públicas no Campo: uma análise do Relatório da II PNERA (1998-2011) In: COELHO, Fabiano; CAMACHO, Rodrigo Simão. O Campo no Brasil Contemporâneo: do governo FHC aos governos Petistas (Questão Agrária e Reforma Agrária - vol. I). Curitiba: CRV, 2018. v. 1, p. 297-324.

FERNANDES, Bernardo Mançano. Diretrizes de uma Caminhada. In: ARROYO, Miguel G; CALDART, Roseli Salete; MOLINA, Mônica Castagna (Org.). Por uma educação do campo. Petrópolis: Vozes, 2004. p. 133-147.

FONEC. Fórum Nacional de Educação do Campo. Seminário Nacional, Brasília: FONEC, 2017.

FONEC. Fórum Nacional de Educação do Campo: notas para a análise do momento atual da Educação do Campo. Seminário Nacional, Brasília: FONEC, ago. 2012. 
GOULD, Larissa. As conquistas da luta no campo que estão sob a mira de Bolsonaro, Brasil de Fato, São Paulo (SP), 18 abr. 2020. Disponível em:

$<$ https://www.brasildefato.com.br/2020/04/18/video-as-conquistas-da-luta-no-campoque-estao-sob-a-mira-de-bolsonaro>. Acesso em: 18 abr. 2020.

HADDAD, Sérgio. Direito a Educação. CALDART, R. S. et al. (Orgs.). Dicionário da Educação do Campo. Rio de Janeiro: Escola Politécnica de Saúde Joaquim Venâncio; São Paulo: Expressão Popular, 2012. p. 217-223.

MOLINA, Mônica Castagna. Pronera como construção prática e teórica da educação do campo. In: ANDRADE, Marcia Regina; PIERRÔ, Maria Clara Di; MOLINA, Mônica Castagna; JESUS, Sonia Meire Santos Azevedo de et al (Orgs.). A educação na Reforma Agrária em perspectiva. São Paulo: Ação Educativa; Brasília: PRONERA, 2004. p. 61-85.

MOLINA, Monica Castagna; ANTUNES-ROCHA, M. I. Educação do campo: história, práticas e desafios no âmbito das políticas de formação de educadores - reflexões sobre o PRONERA e o PROCAMPO, Revista Reflexão e Ação, Santa Cruz do Sul, 22 (2), p.220-253, 2014.

MST. Fórum Nacional de Educação do Campo denuncia extinção do Pronera. Disponível em: <https://mst.org.br/2020/02/28/forum-nacional-de-educacao-do-campodenuncia-extincao-do-pronera/>. Acesso em: 1 abr. 2020.

MUNARIM, Antonio. Elementos para uma política pública de Educação do Campo. In: MOLINA, Mônica Castagna (Org.). Educação do Campo e Pesquisa: questões para reflexão. Brasília: Ministério do Desenvolvimento Agrário, 2006.

NASCIMENTO, Claudemiro Godoy do. Pedagogia da resistência cultural: um pensar a educação a partir da realidade campesina. In: ENCONTRO REGIONAL DE GEOGRAFIA, 8, 2003, Goiás. [Trabalhos apresentados], [S.L: s.n.], p. 1-11.

VIEIRA, Suzane da Rocha. Uma reflexão acerca do manifesto dos pioneiros da educação nova. Disponível em:

<http://www.histedbr.fe.unicamp.br/acer_histedbr/seminario/seminario7/TRABALHOS /S/Suzane\%20da\%20rocha\%20vieira.pdf >. Acesso em: 05 fev. 2020.

Recebido em 01/05/2020.

Aceito para publicação em 18/01/2021. 